\title{
Desde el Perú con cariño
}

"A Lope Cilleruelo, para que su vida de trabajo sirva de ejemplo a las nuevas generaciones".

Estas palabras las escribí hace unos años en la dedicatoria de un libro. $Y$ siempre me asaltó la idea de escribir una carta. $Y$ la escribí, pero esperaba la ocasión para enviarla. Ahora, desde el Perú, me dirijo a Lope Cilleruelo, pidiéndole que me permita tratarlo de tú, ya que siempre le he tratado de Usted. Hoy me acerco, Lope, para tratarte de tú.

¿Por qué no escribo un artículo? Hay muchas razones para ello. He escrito ya muchos artículos y muchos libros en plan serio y con el peso de toda la metodología científica. Sin embargo, la amistad no me permite escribir al presente un artículo. Es mucho lo que he aprenơido de ti, y es mucho más lo que puede aprenderse. Quizás lo esencial sea revelar cómo la vida se acomoda al pensamiento y cómo el pensamiento se allana a la vida. No escribo un artículo, porque no quiero una vez más -y menos en esta ocasión- aparecer con citas y con notas. La única cita verdadera es con la vida $\mathrm{y}$ cuando la vida nos cita no podemos vivir alejados de su vera, como si ella nos repugnara o nos repeliera.

Por eso hoy te escribo desde este Perú, convulsionado por la vida, por una existencia que se debate entre la juventud y la adultez, desde este Perú que sabe de angustias y de necesidades, que vive de pobrezas siendo rico y que pena por surgir del subdesarrollo, pero está sometido a las grandes potencias que no le permiten la libertad. y la independencia que él anhela. Ahora, desde Perú toman cuerpo las ideas y sobre todo grita muy fuerte la vida. Por eso hoy te escribo, para decirte cuánto he aprendido de ti y cuánto puedes seguir enseñando, aunque nadie quiera escuchar tu mensaje y el fuerte grito de tu vida silenciosa.

\section{Yo aprendi}

No entra todo esto en el baúl de los recuerdos olvidados, porque 
el recuerdo significa evocación y constante presencia. Yo aprendí en lo humano la humanidad y la altura de miras. He visto a través de la historia que la vida de los hombres grandes se ha sellado siempre con el sigilo de una gran humanidad. "Nada de lo humano me es ajeno", dijo Terencio, y Agustín de Hipona, recogiendo el mensaje, añadió que "no tengo fibra córnea", como indicando que además de la humanidad le surcaba una vena de sensibilidad y de adhesión, una ternura que iba implícita en toda su actividad.

Yo aprendí esa humanidad gallarda, esa comprensión y esa sinceridad que sólo es producto de las almas limpias. Comprender es difícil, pero indica una amplitud y una emigración, un salir fuera de sí mismo, integrarse en el otro y ponerse en su lugar y desde allí entrever todos los problemas y su planteamiento, revisando las soluciones del otro. Lope, tú has sido siempre el hombre que emigrante de la propia tierra, sin perder la nacionalidad, aunque la cambie, se acomoda al modo de ser y de obrar del otro a quien emigras. Algo de aquello que Agustín de Hipona replicaba en unas cartas famosas, que los tradicionalistas nunca han querido leer en su integridad.

Sólo comprende quien entiende. Y Lope comprende porque entiende, porque nada de lo humano le es ajeno, porque ha surcado los caminos ocultos del ser humano y se ha embarrado en ellos, sin preocuparse de que su calzado estuviera cargado de lodo. Quien comprende a quien se mancha, no se enloda, y quien se enloda comprendiendo, su comprensión ha sido siempre impura. Por eso, la comprensión de Lope no ha sido nunca debilidad o apatía, no ha sido bajeza ni rezago, no ha sido deseo de agradar, sino humanidad, adherido a las fibras más profundas de la persona. Porque ha llegado a tanto su comprensión, que ha sabido perdonar hasta a aquellos que han enlodado su nombre y a aquellos que han jugado a amigos y se han comportado como francotiradores.

$\mathrm{Y}$ aprendi -ibendita lección! - el trabajo. Si hace años, cuando el trabajo quedó integrado a la pobreza, se opusieron mil razones y se dieron mil excusas, sintiéndose más de uno herido, hoy la idea se afinca más en la realidad y está abriéndose paso por sí sóla. El trabajo es creador, es la manifestación más real de la persona humana, es el único modo que tiene el hombre para desarrollarse y realizarse, de tal suerte que quien no trabaja, termina por ser imperfecto, por permanecer en su deficiente configuración. No se trata únicamente del trabajo como medio de subsistencia, sino como medio de comunicación y de expresión de la inalienable originalidad del hombre. El trabajo no pertenece al "tener", sino al "ser" 
del hombre, y es más quien trabaja más, porque a su ser radical añade su avance.

Trabajar no es sentido materialista de la existencia, sino principio generador de asimilación a la Divinidad que, siendo pura Actividad, ha creado para que el hombre continúe su obra. Y trabajando el hombre se perfecciona y mejora. Quien no llega a este convencimiento y a esta realización, queda sin desarrollar. No en vano quien impone como necesidad el trabajo, es tachado de materialista. Hay quienes no se percatan de que sólo podemos elevar el mundo y la realidad que nos rodea, transformándola por medio de la actividad y "humanizándola", dándole el sello personal. Y esto aprendí de Lope Cilleruelo, para quien el trabajo no tenia secreto y quien ha tomado tan en serio el trabajo que se ha realizado en plenitud, entregándose en cuerpo y alma a colaborar con Diós en la mejora del mundo y de las cosas.

$Y$ aunque sea difícil, yo aprendí de Lope una lección que él ha hecho siempre vida propia: La alegria y el humor. Dificil para quien se cansa diariamente trabajando y recibe la insensatez por premio y bonificación a sus desvelos. El humor de Lope quitaba seriedad a las cosas cuando las personas se dejaban llevar por sus pasiones. El hombre que sabe someter el hígado a la razón e impone orden en busca de equilibrio, cuando la realidad se vuelve esquiva, es un hombre superior. Estar en el momento y saber acomodarse a él, dar alegria cuando todo invita a la tristeza y a la dejadez es una ciencia difícil que sólo personas superiores son capaces de ensen̂́ar. $Y$ en este sentido Lope es un maestro acabado. Muchos han pensado que su humor nacia de otras fuentes, pero no se han detenido a pensar qué significa la gracia del payaso bajo su manto de máscara, consciente de que su propia madre está muriendo. Así, con está límpida imagen, expreso en alguna ocasión, su función de aliento y alegria. Consta en escrito. Esa es su vida y esas son sus tareas y sus intenciones. Aquello que tantas veces oi "cosas de Lope", hoy lo veo muy claro. No han sabido leer en su mundo y siguen sin percatarse de que la vida sólo es fácil cuando el hombre es capaz de darle un sentido. ¡Qué triste sentir que el propio mensaje se desvirtúa en base a razones secundarias que nada tienen que ver con lo esencial en la existencia! Reir, cuando el espíritu llora, es animarse con deseos de no sucumbir a la angustia universal. "Yo esto ya lo ví, al finalizar la guerra". Sí, era verdad. Todo sucedió por no saber estar a la altura de los tiempos, por no saber caminar con la historia $\mathrm{y}$ perder el tren de la misma. Lope ha sido faro $\mathrm{y}$ guia y solamente han tropezado quienes han cerrado los ojos. 
Desprendimiento $y$ modestia

El genio siempre es humilde. Yo he aprendido de Lope Cilleruelo el desprendimiento y la humildad. He entendido la despreocupación y la modestia del sabio, que sabe sus propias limitaciones y entiende que ven más cuatro ojos que dos.

Desprenderse significa que uno ha estado prendido de algo, y ordinariamente todos estamos prendidos de nosotros mismos. Saber desprenderse es luchar contra el egoísmo diariamente y entregarse a los demás, como si uno no tuviera otra cosa que hacer. Dejar 10 propio por preocuparse de los demás impone sacrificios que sólo un amor sincero puede permitirse.

Pero todo esto nace de algo mucho más profundo. La conciencia de la propia limitación exige valorar a los demás y sentir la propia deficiencia y el propio abandono. Cuando uno siente su limitación, necesariamente debe apelar a los demás. Así, con esa sencillez, con esa valentía que estimula la honradez, puede pedirse a la juventud: "Revisa, porque de esto entiendes tú mucho más que yo". Porque además la propia limitación compromete la comprensión de los demás y valorarlos en su auténtico sentido. Por eso es más apreciable el desprendimiento y más subida, la modestia. La raí está en la hondura de la propia imperfección.

$Y$ el desprendimiento y la comprensión, me han enseñado otra gran lección: saber escuchar y dialogar. Yo lo aprendi de la vida de este hombre que sabe de la tragedia humana. Yo aprendí a escuchar, a entrar en los demás, a oir sus motivos. Porque sólo una vez que se ha escuchado, se puede responder, se puede aportar algo nuevo, recogiendo lo valorable en los demás e integrándolo como verdad, belleza o amor en la propia existencia. Y escuchando, aprendí a dialogar con el ascetismo que todo diálogo impone. Escuchar significa preocuparse por los demás, por aquello que tienen de más personal y auténtico que son sus palabras, y aceptar sus ideas y sus proyectos. Era difícil, yo lo entiendo. Pero Lope sabía hacerlo $\mathrm{y}$ al hacerlo, lo comunicaba a quien no estaba cegado por egoismos falsos.

Aceptar ideas y proyectos, vengan de donde vinieren. $Y$ aceptar de la juventud, de otras edades; de otras generaciones es virtud máxima de este hombre abierto. Por eso aprendi la apertura y la comunicación. Siempre se aprende y cada ser humano tiene sus razones que complementan las propias, no se oponen a ellas. Yo aprendí que estos valores son frutos de un gran espíritu de caridad, que pone en marcha una fe honda y arraigada. Fe que Lope ha impreso 
con sello indeleble en su existencia, caminando entre la espina aguda de la indiferencia, cubierta con manto de mistica barata.

Y aprendí - ¡y cuánto me ha servido! - una sensibilidad exquisita. Muchos pensaron que en Lope no había sentimientos ni sensibilidad exquisita. ¿Qué gran error! Lope tiene su gran corazón y una sensibilidad que ha manifestado y manifiesta en su alma de artista, de pintor, de escultor, de poeta y de músico. Yo lo he visto conservar como reliquia inapreciable cuanto sus "jóvenes" le ofrecian como homenaje, pobre en lo físico, pero rico en sentimientos. Sensibilidad de artista, que ha sabido dominar equilibrándola con la fuerza de su razón. No hay desequilibrios en esa personalidad y si existen, son lucha por conseguirlo.

Hay una ciencia oculta para muchos, descubierta por pocos, que aprendí de este maestro inigualable: el descanso, el ocio y el tiempo libre. Distraerse en actividades distintas a las monótonas de cada día y hora es la verdad de quien sabe vivir para dar más. Saber descansar es ciencia difícil, porque descansar no es no hacer nada -el hombre se desarrolla en el trabajo-, sino el hacer algo que desarrolla sin herir las delicadas partes afectadas. Es conjunción ideal de cuanto la vida nos depara. Conjugar el trabajo y el ocio es tarea ardua, porque siempre el trabajo puede trocarse en ocio, y el ocio. tornarse trabajo, cuando se descansa en función de un mayor rendimiento. Lope ha sabido hacerlo siempre en su vida y aún a sus. años nos muestra, como ejemplo, esta veta tan vasta hoy en una sociedad atormentada por la prisa y la velocidad.

\section{Libertad}

Yo aprendi la libertad total o integral, no el sometimiento irracional y gregario. $\mathrm{Y}$ aprendí la libertad por la liberación, Sólo es libre quien se ha liberado, y la liberación es arte personal, ciencia precisa: liberación de la pasión, del odio, del egoismo y de la inconsciencia, liberación de cuanto no permita actuar con libertad para llegar a ser auténticamente libre. Porque la libertad se aprende de modo no teórico, sino práctico. Necesita maestros de vida $y$ Lope es un maestro de vida y para la vida. Libre ante la ley y ante las personas, no esclavo de leyes ni de personas, pero siempre respetuoso de las leyes y de las personas. La libertad es honradez ante Dios y ante si mismo, y respeto sincero de los demás. Así aprendí a ser libre yo por la verdad y por el amor, no esclavo de la hipocresía, de la envidia o del odió. Amigo de los hombres, pero más amigo de la verdad $\mathrm{y}$ de la justicia $\mathrm{y}$ del amor. 
Y aprendí a considerar al hombre como amigo y compañero, como caminante sacrificado hacia una meta alentada por la esperanza de su consecución, proyectada por una fe que pasa por la existencia, aceptando lo que no puede cambiar y cambiando, habida cuenta del tiempo y de la situación, lo que pueda mejorarse. Y aprendi que el tiempo forma parte de la existencia humana, ya que sólo en el tiempo podemos realizarnos como proyecto divino que culminará en ese final sin fronteras que es la Divinidad. El tiempo se hace proyección del espiritu y es base de la impaciencia humana, siendo a su vez generador de producción. Ser temporal es sentirse hombre: "Dios es paciente porque es eterno... Luego el hombre es impaciente por... temporal".

Aprendí que en lo humano existe el hombre, siendo accidental la diferencia entre varón y mujer. Tảl vez para el apóstol la psicología exija métodos distintos, pero la metafísica de los sexos impone la igualdad radicál del ser humano. Apóstol sin diferencias, siempre adherido al ideal que lo arrastra, ése es Lope. La mujer se integró a su vida y fue siempre aguijón de completez humana y entre ellas realizó su mensaje sin distinción, basado siempre en la verdad que heria.

Y en todo existió para mi una gran lección: la reflexión profunda y el escuchar el mensaje de las cosas, leer a Dios en sus manifestaciones. Reflexionar sobre toda la realidad, sobre los acontecimientos, extraer de cada acción su mensaje y de cada realidad su apremiante urgencia; ha sido la lección más realista y efectiva de la existencia de Lope sobre la mía. Me convenciste, Lope. Asi he vivido y en ello continúo viviendo. No lo desprecies.

\section{Asi yo lo aprendí}

Quizás yo lo aprendí sin que él me lo enseñara. o tal vez él dirá que hiero su modestia al valorar aquello en que no habia reparado. Sin embargo, es la vida quien habla sin palabras. Yo lo aprendi temprano, lo he vivido y puedo asegurar que para mi felicidad y la de los mios hoy. Y ciertamente que no lo olvidaré.

tope no ha retorcido la vida para adaptarla a las ideas, ni ha recortado las ideas para acomodarlas a la vida. Fluye todo en él con normalidad, sin estridencias. Ha seguido una línea y en ella ha encontrado a los grandes de la historia. Para él no existe las fronteras. Tres hombres y uno es Dios: Jesús, Pablo de Tarso y Agustín de Hipona. Y en torno a ellos ha enhebrado su mundo y sus concepciones. No se quedó en la historia, la hizo; la ha vivido, la hace 
y va viviendo. Su vida es pensamiento puro y su pensamiento es vida iluminada. El descubrió a Agustín, conjunción de pensamiento griego $\mathrm{y}$ hebreo, $\mathrm{y}$ visión clara de vida $\mathrm{y}$ fe profunda. $\mathrm{Y}$ ha visto su concepción proyectada a través de la historia. Sus artículos lo revelan ampliamente. Lope ha encontrado un punto y con él ha movido el mundo.

Comparando a Jesús, a Pablo y a Agustín y lo escrito por Lope sobre ellos con la realidad de vida de Cilleruelo, he llegado al convencimiento de que el resumen más perfecto de la interpretación cillerueliana de Agustín es su vida. Porque hay que decirlo claro: Agustín se "pega" y "pega" fuerte. Y a san Agustín sólo puede comprendérselo viviéndolo, Agustín sólo puede ser entendido desde la vida. Entrar en la vida de Agustín para vivir desde dentro comprendiéndolo exige entrega, abertura, emigración y, al final, integración. Algo así ha sido la existencia de Lope Cilleruelo.

\section{Una carta mejor}

Por todo esto, un artículo me pareció muy frío. Preferí escribir desde la vida, porque así lo aprendí a una triple escuela: la de Jesús, la de Agustín y la de Lope Cilleruelo. Son ellos quienes me han dicho algo y son las únicas personas cuyo silencio me ha honrado con su presencia, cuando he intentado hablar yo. Son sus voces las que deben escucharse aquí en América. Voz de amor y de verdad, voz de justicia y de paz, voz de aliento y de esperanza, voz de trabajo y paciencia, voz de alegría y de hogar, voz de violencia y fuerza. Voz de vida.

Si algo más tuviera que añadir, diría que si "el porvenir de la humanidad está en manos de quien sepa ofrecer a las nuevas generaciones razones para vivir y motivos para esperar", las nuevas generaciones tienen el porvenir en sus manos. Lope "ofrece razones para vivir y motivos para esperar". ¡Ojalá haya muchos que recojan su mensaje!

Espero, Lope, no haber herido tu modestia. Tal vez dirás, que no me has enseñado esto. Pero yo puedo decirte que de ti lo he aprendido. Es el homenaje de una vida que ha cambiado de rumbo, pero no de profundidad ni de convencimientos. Recíbelo como tal. Desde el Perú con cariño. 